\title{
Monotherapy of androgen deprivation therapy versus radical prostatectomy among veterans with localized prostate cancer: comparative effectiveness analysis of retrospective cohorts
}

\author{
This article was published in the following Dove Press journal: \\ Comparative Effectiveness Research \\ 26 April 2012 \\ Number of times this article has been viewed
}

Jinan Liu' ${ }^{1,2}$

Lizheng Shi ${ }^{1,2,3}$

Oliver Sartor ${ }^{3}$

'Tulane University, School of Public Health and Tropical Medicine, ${ }^{2}$ Southeast Louisiana Veterans Health Care System, Tulane University, ${ }^{3}$ School of Medicine and Tulane Cancer Center, New Orleans, LA, USA
Correspondence: Jinan Liu Tulane University, School of Public Health and Tropical Medicine, Tulane University, I440 Canal Street, Suite 1900, New Orleans, LA 70II2, USA

$\mathrm{Tel}+\mathrm{I} 5048107282$

Fax +I 5049883783

Email jliu4@tulane.edu
Background: This retrospective cohort study aimed to examine the comparative effectiveness of monotherapy of primary androgen deprivation therapy or radical prostatectomy.

Methods: Male patients with localized prostate cancer (T1-T2, N0, M0) were identified in the Veterans Affairs Veterans Integrated Service Network 16 data warehouse (January 2003 to June 2006), with one-year baseline and at least three-year follow-up data (until June 2009). Patients were required to be 18-75 years old and without other recorded cancer history. The initiation of primary androgen deprivation therapy or monotherapy of radical prostatectomy within six months after the first diagnosis of prostate cancer was used as the index date. Primary androgen deprivation therapy patients were matched to the radical prostatectomy patients via propensity score, which was predicted from a logistic regression of treatment selection (primary androgen deprivation therapy versus radical prostatectomy) on age, race, marital status, insurance type, cancer stage, Charlson comorbidity index, and alcohol and tobacco use. The overall survival from initiation of index treatment was then analyzed using the Kaplan-Meier and Cox proportional hazards model.

Results: The two cohorts were well matched at baseline (all $P>0.05$ ). During a median follow-up of 4.3 years, the cumulative incidence of death was $13(10.57 \%)$ among 123 primary androgen deprivation therapy patients and four (3.25\%) among 123 radical prostatectomy patients $(P<0.05)$. The overall three-year survival rate was $92.68 \%$ for primary androgen deprivation therapy and $98.37 \%$ for radical prostatectomy $(P<0.05)$. Patients who received primary androgen deprivation therapy had almost three times as high a mortality risk as those using radical prostatectomy (hazards ratio 3.388, 95\% confidence interval 1.094-10.492, $P=0.034$ ).

Conclusion: After propensity score matching, overall three-year survival rate following radical prostatectomy among patients with localized prostate cancer was significantly higher than that after primary androgen deprivation therapy.

Keywords: prostate cancer, primary androgen deprivation therapy, radical prostatectomy, survival rate

\section{Introduction}

Prostate cancer is the most common malignancy in men. ${ }^{1}$ In 2009, new cases of prostate cancer were estimated over 190,000, and the disease also causes approximately 30,000 deaths per year in the United States. ${ }^{2}$ Approximately $80 \%$ of patients with prostate cancer were diagnosed at clinically localized or regional stages. ${ }^{3}$ They are often treated with active surveillance, surgery, androgen deprivation therapy, or radiation. We note that the National Comprehensive Cancer Network practice guidelines for management 
include all of the above except for androgen deprivation therapy as monotherapy. ${ }^{4}$

Despite the lack of support, primary androgen deprivation therapy has become a common choice for clinically localized patients. According to the Cancer of the Prostate Strategic Urologic Research Endeavor (CaPSURE) database, 14.4\% of clinically localized patients received primary androgen deprivation therapy. ${ }^{5}$ The common use of primary androgen deprivation therapy in patients with localized prostate cancer may be because several studies support the use of androgen deprivation therapy in patients with metastatic disease or with high-risk cancer, in combination with radiation therapy or as adjuvant therapy for node-positive patients after radical prostatectomy. ${ }^{6-9}$ While the optimal timing of androgen deprivation therapy also remains controversial, ${ }^{10}$ no randomized controlled studies have evaluated androgen deprivation monotherapy in patients with low-risk cancer. Further, large population-based studies observed inferior survival following primary androgen deprivation therapy compared with watchful waiting. ${ }^{11,12}$

On the other hand, radical prostatectomy is a commonly used cure attempt for clinically localized patients, with an estimate of 60,000 radical prostatectomies performed annually in the United States. ${ }^{13}$ Its clinical benefit in patients at an early stage has been demonstrated in Scandinavian Prostate Cancer Group Study Number 4. ${ }^{14}$ However, the patients were not typically detected by prostate-specific antigen screening in this study. These results might or might not apply to today's patients in the United States, who are identified primarily by prostate-specific antigen-induced prostate biopsies. Ongoing studies are evaluating surveillance as a control group in this setting and require prolonged periods of follow-up to draw a conclusion. ${ }^{13,15}$

There is no randomized controlled trial to compare primary androgen deprivation therapy with radical prostatectomy in the literature, and no such study is ongoing to our knowledge. In this retrospective cohort study, we examined the overall survival rate of localized prostate cancer using either primary androgen deprivation therapy or radical prostatectomy as monotherapy in the Veterans Affairs health system.

\section{Materials and methods}

\section{Data source}

This study was a retrospective analysis of patients with prostate cancer in the Veterans Integrated Service Network (VISN) 16. VISN 16 is one of the 23 VISNs of the Department of Veterans Affairs, serving veterans in Arkansas, Louisiana, Mississippi,
Oklahoma, and parts of Alabama, Florida, Missouri, and Texas. The database contains demographic data, inpatient and outpatient activities, pharmacy prescriptions, laboratory results, and mortality information (date of death) for each patient treated within the network. A tumor registry, which captures data on cancer stage and therapies in the network, is also available. The data warehouse is updated monthly and maintained by the VISN 16 Information Technology Development Group. Data covering the period from January 1, 2002, to June 30, 2009, were extracted. Both Tulane and Veterans Health Administration institutional review boards and Veterans Health Administration Research and Development approved this study protocol. All patient identifiers were removed. Data format and content were in compliance with the Health Insurance Portability and Accountability Act requirements.

\section{Sample selection}

Figure 1 summarizes the sample selection process. Patients were included in the study if they had at least one diagnosis of prostate cancer (International Classification of Disease-9-Clinical Modification [ICD-9-CM] 185.xx). Prostate cancer diagnoses were confirmed by the inclusion of patients in the VISN 16 cancer registry. The participants were required to have records of clinically localized prostate cancer patients (T1-T2, N0, M0). Further inclusion criteria included: initiation of androgen deprivation therapy or radical prostatectomy between January 1, 2003 and June 30, 2006 to ensure one-year study baseline and at least three years follow-up (until June 30, 2009); either androgen deprivation therapy or radical prostatectomy as monotherapy was initiated within six months after first diagnosis of prostate cancer; age 18-75 years; and no documented cancer history before prostate cancer diagnosis. Patients who had ever received radiation therapy were excluded from this study.

\section{Treatments}

Androgen deprivation therapy was identified utilizing a reported algorithm, ${ }^{16}$ including the Healthcare Common Procedure Coding System [HCPCS] codes for orchiectomy: 54520, $54521,54522,54530,54535$ or ICD-9-CM code of 62.4, and the HCPCS codes for luteinizing hormone releasing hormone (LHRH) agonists: J1950, J9202, J9218, or J9219. radical prostatectomy was indentified using the HCPCS codes: 55821, $55801,55810,55812,55815,55831,55840,55842,55845$ or ICD-9-CM code: $60.3,60.4,60.5,60.6$, and 60.62. ${ }^{17}$

\section{Outcome}

Survival was defined as the interval from the initiation of treatment to the date of death. Patients were followed from 


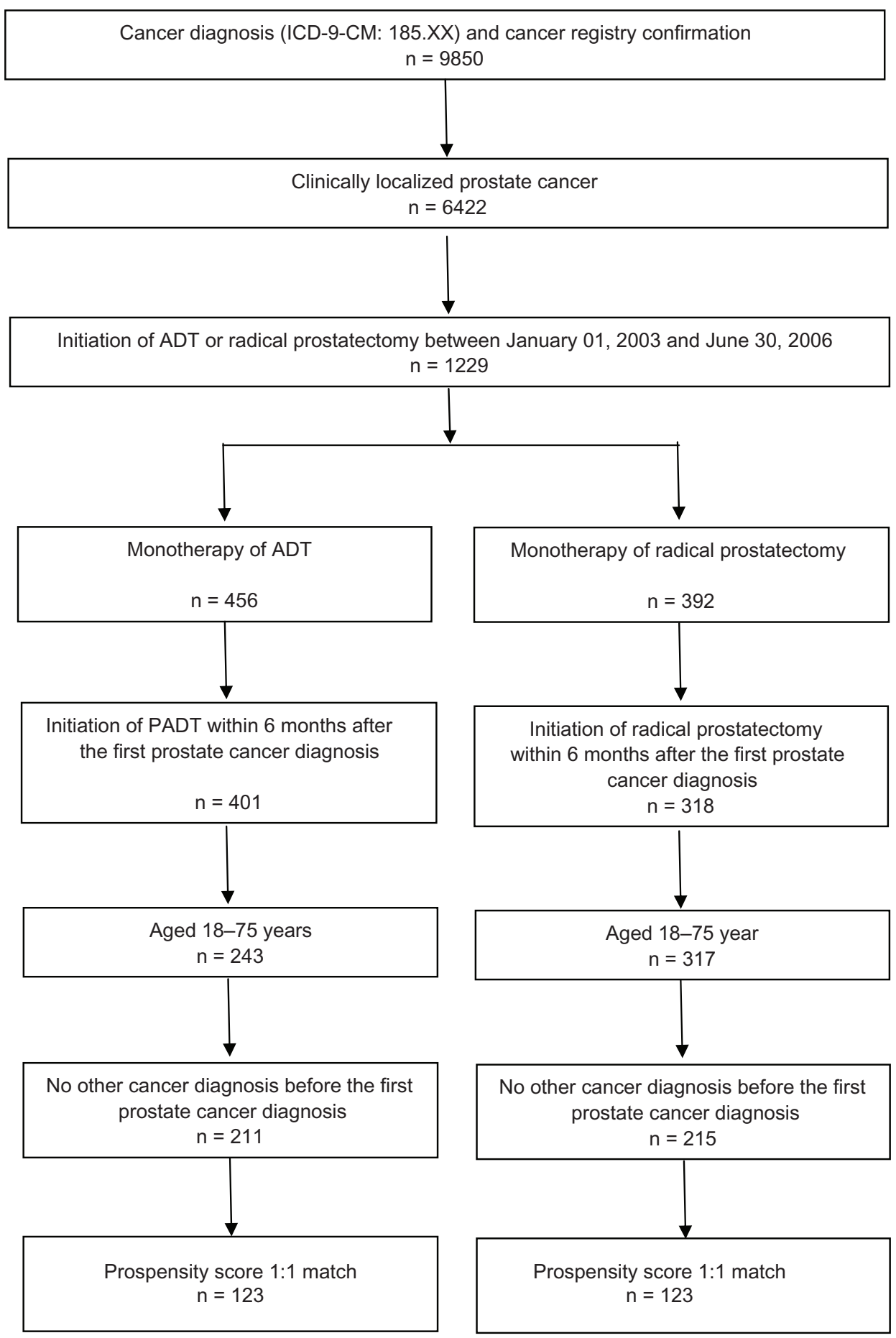

Figure I Flow chart for selection of patients with clinically localized prostate cancer. Abbreviations: ADT, androgen deprivation therapy; PADT, primary androgen deprivation therapy.

their treatment initiation date to death, or were censored at the end of data availability (until June 30, 2009).

\section{Statistical analyses}

Propensity score matching was used to adjust for treatment selection bias, which is expected in observational studies due to lack of randomization. ${ }^{18}$ After matching, two cohorts with comparable baseline information were expected, and this was, in fact, obtained. Specifically, the propensity scores were assessed from a logistic regression that estimated the probability of receiving primary androgen deprivation therapy versus radical prostatectomy, using age at the first prostate cancer diagnosis, race, marital status, insurance type, cancer stage, Charlson comorbidity index,${ }^{19}$ and alcohol and tobacco 
use as the explanatory variables. A radical prostatectomy patient was then matched with a primary androgen deprivation therapy patient if their predicted probability were the closest, with a maximum distance tolerance of $0.1 .^{18}$ Chi-square tests for categorical variables and paired $t$-tests for continuous variables were used to verify that the baseline characteristics were comparable after matching.

Overall survival rate was analyzed using the Kaplan-Meier method, and hazard ratios were estimated using Cox proportional hazard regression, adjusted for age at first prostate cancer diagnosis, race, marital status, insurance type, cancer stage, Charlson comorbidity index, and tobacco and alcohol use.

\section{Results}

Among 1229 localized patients with prostate cancer, 456 (37.1\%) received primary androgen deprivation therapy and $392(31.9 \%)$ used radical prostatectomy. A total of 426 patients met all the study inclusion criteria, ie, 211 patients in the primary androgen deprivation therapy group and 215 in the radical prostatectomy group. Before propensity score matching, patients in the primary androgen deprivation therapy group were older $(P<0.001)$, with a higher Charlson comorbidity index score $(P<0.001)$, less likely to be black $(P=0.027)$, less likely to have other insurance $(P<0.001)$, and less likely to be tobacco $(P=0.008)$ and alcohol users $(P=0.020)$. No difference in marital status $(P=0.057)$ and baseline cancer stage $(P=0.127)$ was found between the groups. Detailed information is available in Table 1.

After 1:1 propensity score matching, the final sample of this study was 246 , ie, 123 patients in the primary androgen deprivation therapy cohort and 123 in the matched radical prostatectomy cohort. All 123 patients in the primary androgen deprivation therapy cohort used LHRH agonists in this study. The mean age was $62.9 \pm 5.50$ years in the primary androgen deprivation therapy patients, and $62.5 \pm 4.95$ years in the radical prostatectomy patients. Charlson comorbidity index

Table I Baseline characteristics of primary androgen deprivation therapy cohort versus radical prostatectomy cohort before and after propensity score match

\begin{tabular}{|c|c|c|c|c|c|c|}
\hline & $\begin{array}{l}\text { PADT } \\
(n=2 I I)\end{array}$ & $\begin{array}{l}R P \\
(n=215)\end{array}$ & $\begin{array}{l}P \text { values } \\
\text { before match }\end{array}$ & $\begin{array}{l}\text { Matched PADT } \\
(n=123)\end{array}$ & $\begin{array}{l}\text { Matched RP } \\
(n=123)\end{array}$ & $\begin{array}{l}P \text { values } \\
\text { after match }\end{array}$ \\
\hline Age, years* & $66.2(6.07)$ & $59.9(6.15)$ & $<0.001$ & $62.9(5.50)$ & $62.5(4.95)$ & 0.386 \\
\hline Age, years & & & $<0.001$ & & & 0.678 \\
\hline$<65$ & 93 (44.08\%) & I7I (79.53\%) & & 87 (70.73\%) & 84 (68.29\%) & \\
\hline$\geq 65$ & I I 8 (55.92\%) & 44 (20.47\%) & & 36 (29.27\%) & 39 (31.71\%) & \\
\hline Race & & & 0.027 & & & 0.655 \\
\hline White & I2I (57.35\%) & $|2|$ (56.28\%) & & 72 (58.54\%) & 7I (57.72\%) & \\
\hline Black & 58 (27.49\%) & 77 (35.81\%) & & 42 (34.15\%) & 39 (31.71\%) & \\
\hline Others & $32(15.17 \%)$ & 17 (7.91\%) & & $9(7.31 \%)$ & $13(10.57 \%)$ & \\
\hline Marital status & & & 0.570 & & & 0.796 \\
\hline Married & III (52.6I\%) & $119(55.35 \%)$ & & 72 (58.54\%) & 70 (56.91\%) & \\
\hline Others & 100 (47.39\%) & 96 (44.65\%) & & 51 (4I.46\%) & $53(43.09 \%)$ & \\
\hline $\begin{array}{l}\text { Insurance other } \\
\text { than VA }\end{array}$ & & & $<0.001$ & & & 0.523 \\
\hline Yes & 71 (33.65\%) & $129(60.00 \%)$ & & 56 (45.53\%) & $6 \mathrm{I}(49.59 \%)$ & \\
\hline No & 140 (66.35\%) & $86(40.00 \%)$ & & 67 (54.47\%) & $62(50.41 \%)$ & \\
\hline Cancer stage & & & 0.127 & & & 1.000 \\
\hline$\leq \mathrm{T} 2 \mathrm{a}$ & I9I (90.52\%) & 203 (94.42\%) & & II 3 (9I.87\%) & II 3 (9I.87\%) & \\
\hline$>\mathrm{T} 2 \mathrm{a}$ & $20(9.48 \%)$ & 12 (5.58\%) & & $10(8.13 \%)$ & $10(8.13 \%)$ & \\
\hline $\mathrm{CCl}^{*}$ & $0.8(0.64)$ & $0.3(0.2 \mathrm{I})$ & $<0.001$ & $0.6(1.20)$ & $0.5(1.08)$ & 0.821 \\
\hline $\mathrm{CCl}$ & & & $<0.001$ & & & 0.921 \\
\hline 0 & I 22 (57.82\%) & I 74 (80.93\%) & & 89 (72.36\%) & 87 (70.73\%) & \\
\hline I & $53(25.12 \%)$ & 25 (11.63\%) & & 21 (17.07\%) & $21(17.07 \%)$ & \\
\hline$\geq 2$ & $36(17.06 \%)$ & $16(7.44 \%)$ & & $13(10.57 \%)$ & $15(12.20 \%)$ & \\
\hline Tobacco user & & & 0.008 & & & 0.438 \\
\hline Yes & 109 (5I.66\%) & 138 (64.19\%) & & 75 (60.98\%) & 69 (56.10\%) & \\
\hline No & 102 (48.34\%) & 77 (35.8I\%) & & 48 (39.02\%) & 54 (43.90\%) & \\
\hline Alcohol user & & & 0.020 & & & 0.691 \\
\hline Yes & 59 (27.96\%) & 83 (38.60\%) & & 43 (34.96\%) & 46 (37.40\%) & \\
\hline No & 152 (72.04\%) & I 32 (6I. $.40 \%)$ & & 80 (65.04\%) & 77 (62.60\%) & \\
\hline
\end{tabular}

Note: *Data presented as mean \pm standard deviation.

Abbreviations: $\mathrm{CCl}$, Charlson comorbidity index; RP, radical prostatectomy; PADT, primary androgen deprivation therapy; VA, Veterans Affairs. 
was $0.6 \pm 1.20$ years in primary androgen deprivation therapy and $0.5 \pm 1.08$ years in radical prostatectomy patients. After matching by propensity scoring, all baseline variables were equivalent between the two groups (all $P$ values $>0.05$ ).

The median follow-up was 4.3 years in the primary androgen deprivation therapy cohort and 4.2 years in the radical prostatectomy cohort. During the follow-up period, the cumulative incidence of death was 13 (10.57\%) among 123 primary androgen deprivation therapy-treated patients and four (3.25\%) among 123 radical prostatectomy-treated patients. According to the Kaplan-Meier curves (Figure 2), the overall three-year survival rate was $92.68 \%$ in primary androgen deprivation therapy cohort and $98.37 \%$ in the radical prostatectomy cohort $(P=0.028)$. The Cox proportional hazard regression results are presented in Table 2. Patients who underwent primary androgen deprivation therapy had almost three times mortality risk as those using radical prostatectomy (hazards ratio $3.388,95 \%$ confidence interval $=1.094-10.492, P=0.034)$. All other explanatory variables, including age, race, marital status, insurance, cancer stage, Charlson comorbidity index, tobacco use, and alcohol use, were not statistically significant (all $P$ values $>0.05$ ).

\section{Discussion}

Though prior data from studies have compared the utilization of early versus delayed androgen deprivation therapy use $^{10}$ and radiotherapy versus radiotherapy combined with androgen deprivation therapy, ${ }^{8}$ this is the first study which attempts to explore the comparative effectiveness between primary androgen deprivation therapy and radical prostatectomy among patients with localized prostate cancer.

According to our study, primary androgen deprivation therapy was related to a three-fold higher risk of death than radical prostatectomy.

Previous studies have also reported that higher death rates are associated with this form of therapy. ${ }^{17}$ Physiologic effects of primary androgen deprivation therapy, such as weight gain, muscle mass reduction, and changes in lipids may lead to exacerbation of potentially more serious conditions, such as hypertension, diabetes, and coronary artery disease. ${ }^{20}$ Androgen deprivation therapy has also been related to a higher risk of fracture, ${ }^{16}$ diabetes, and possible coronary heart disease, ${ }^{21}$ and has adverse effects on quality of life. ${ }^{22}$ These results indicate that androgen deprivation therapy alone may not be an appropriate therapeutic choice for the population with localized prostate cancer. However, primary androgen deprivation therapy seems to be overutilized for patients with localized prostate cancer in Veterans Affairs during this period. Specifically, more than one third of the localized population received primary androgen deprivation therapy in the study, as compared with $14.4 \%$ in the CaPSURE database; ${ }^{23}$ more people treated with primary

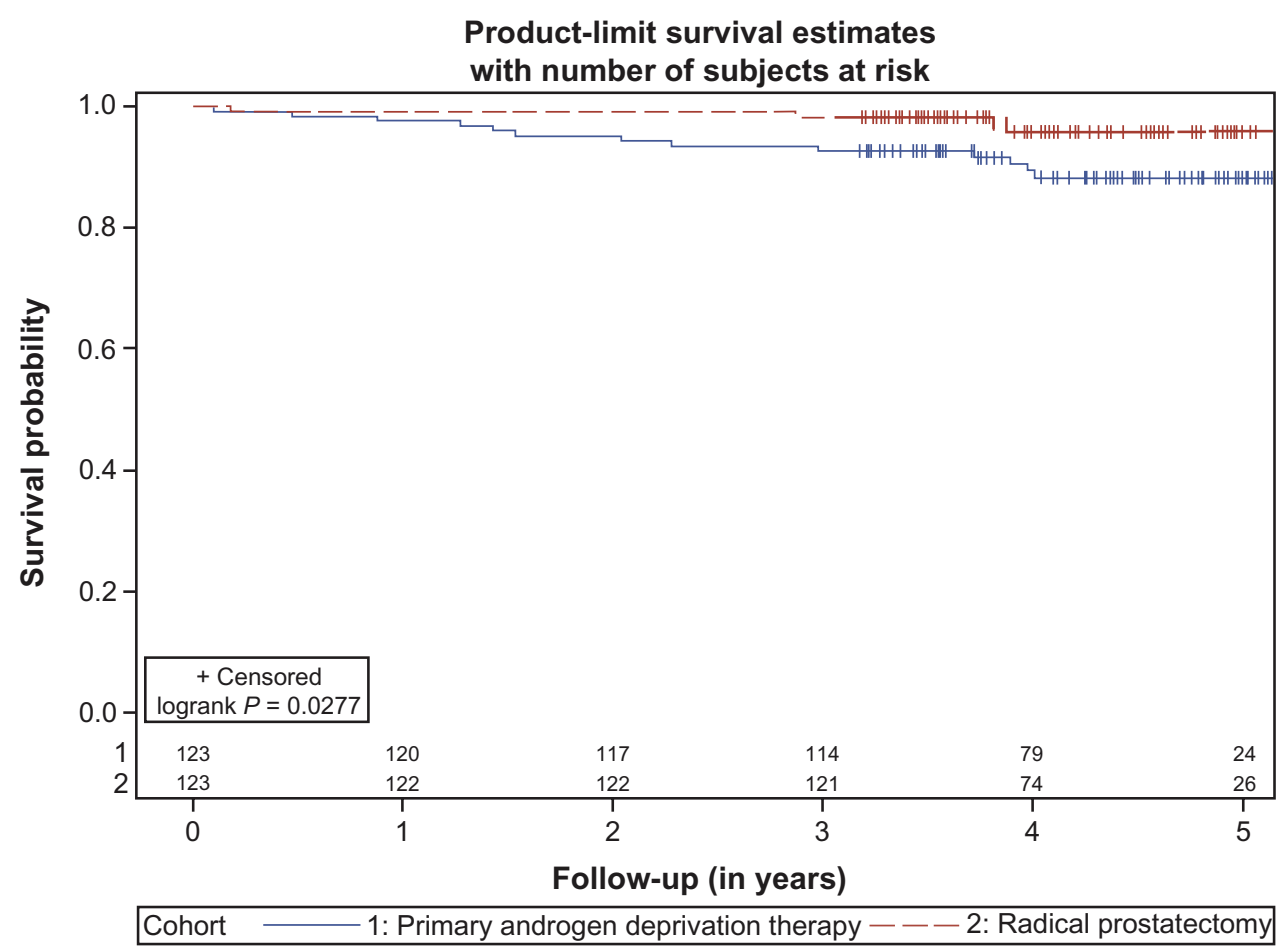

Figure 2 Overall survival in primary androgen deprivation therapy cohort versus radical prostatectomy cohort after propensity match. 
Table 2 Hazard risk of death among localized prostate cancer patients according to Cox proportional hazard regression after propensity score match

\begin{tabular}{|c|c|c|c|}
\hline & Hazards ratio & 95\% Confidence interval & $P$ values \\
\hline Treatment (reference RP) & & & 0.034 \\
\hline PADT & 3.388 & $(1.094,10.492)$ & \\
\hline Age (reference $\leq 65$ ) & & & 0.793 \\
\hline$\geq 65$ & 1.014 & $(0.916,1.121)$ & \\
\hline \multicolumn{4}{|l|}{ Race (reference, black) } \\
\hline White & 1.198 & $(0.409,3.507)$ & 0.742 \\
\hline Other race & 0.000 & NA & 0.993 \\
\hline Marital status (reference, married) & & & 0.127 \\
\hline Others & 2.243 & $(0.795,6.329)$ & \\
\hline Insurance (reference, VA only) & & & 0.448 \\
\hline Others & 0.657 & $(0.222,1.945)$ & \\
\hline Cancer stage (reference $\leq \mathrm{T} 2 \mathrm{a}$ ) & & & 0.659 \\
\hline$>\mathrm{T} 2 \mathrm{a}$ & 0.629 & $(0.08 I, 4.915)$ & \\
\hline \multicolumn{4}{|l|}{$\mathrm{CCl}$ (reference 0) } \\
\hline 1 & 1.284 & $(0.331,4.982)$ & 0.718 \\
\hline$\geq 2$ & 3.155 & $(0.850,11.709)$ & 0.086 \\
\hline Tobacco user (reference, no) & & & 0.651 \\
\hline Yes & 0.747 & $(0.212,2.64 I)$ & \\
\hline Alcohol user (reference, no) & & & 0.446 \\
\hline Yes & 1.595 & $(0.480,5.304)$ & \\
\hline
\end{tabular}

Abbreviations: $\mathrm{CCl}$, Charlson comorbidity index; RP, radical prostatectomy; NA, not available (because of the zero coefficient and a large $P$ value); PADT, primary androgen deprivation therapy; VA, Veterans Affairs.

androgen deprivation therapy as compared with radical prostatectomy. The reason for the higher rate of primary androgen deprivation therapy in Veterans Affairs than in the CaPSURE population is unclear because no guideline has embraced this form of therapy. A recent study reported that decreased physician reimbursement was related to a reduction of androgen suppression therapy from $10.2 \%$ in 2003 to $6.1 \%$ in 2005 among low-risk prostate cancer patients. ${ }^{24}$ In contrast with private practice, the Veterans Affairs system does not link drug usage to physician reimbursement incentives. The question of how to reduce the inappropriate use of androgen deprivation therapy remains a challenge in the Veterans Affairs system.

Radical prostatectomy patients achieved a comparatively high three-year survival rate in this study, both in univariate analysis and in multivariate analysis adjusted for other baseline variables. Further, randomized trials indicate that radical prostatectomy is a better choice than active surveillance in men with non-prostate-specific antigen-detected cancers. Previous studies have also reported that radical prostatectomy patients have a lower risk of death than watchful waiting patients, so radical prostatectomy is typically regarded as the "gold standard" for localized prostate cancer. ${ }^{25}$ Despite being a known effective therapy, radical prostatectomy is also related to distinct patterns of adverse change in quality of life, particularly sexual and urinary health..$^{25,26}$
This study has several limitations. First, it was an observational study without randomization. Even though we balanced the baseline information between two cohorts using propensity score matching, selection bias may still be an issue due to unobservable variables. For example, important severity measures such as prostate-specific antigen and Gleason score were not available in the registry database. Second, cause of death was not recorded in the Veterans Affairs vital records. Prior studies clearly indicate high non-prostate cancer mortality among prostate cancer patients, even after failure of primary treatment. ${ }^{27}$ But, overall survival rate is still one important aspect to compare two treatments, especially for a study population with an average age of 63 years. Third, localized prostate cancer patients typically have a high overall survival rate, and a substantial number of participants had only a relatively short-term follow-up in this study.

In conclusion, this preliminary comparative effectiveness analysis of overall three-year survival rate found that the cohort of patients with clinically localized prostate cancer and radical prostatectomy had significantly higher survival outcomes than the cohort of patients with primary androgen deprivation therapy. Further analyses of cause of death and longer-term follow-up are warranted to confirm the finding and to understand better the reasons for the mortality observed. 


\section{Disclosure}

No potential conflicts of interest are disclosed. This study has been presented at the 16th annual meeting of the International Society for Pharmacoeconomics and Outcomes Research in Baltimore, MD, May, 2011 and also been reported in the media Renal and Urology News, August 2011.

\section{References}

1. Klein EA, Thompson IM. Update on chemoprevention of prostate cancer. Curr Opin Urol. 2004;14(3):143-149.

2. American Cancer Society. Prosate Cancer. 2009. Available from: http://www.cancer.org/acs/groups/content/@nho/documents/document/ prostatecancerpdf.pdf. Accessed October 15, 2010.

3. Jemal A, Siegel R, Xu J, Ward E. Cancer statistics, 2010. CA Cancer J Clin. 2010;60(5):277-300.

4. Mohler J, Bahnson RR, Boston B, et al. NCCN clinical practice guidelines in oncology: prostate cancer. J Natl Compr Canc Netw. 2010;8(2):162-200.

5. Cooperberg MR, Broering JM, Carroll PR. Time trends and local variation in primary treatment of localized prostate cancer. J Clin Oncol. 2010;28(7):1117-1123.

6. Messing EM, Manola J, Sarosdy M, Wilding G, Crawford ED, Trump D. Immediate hormonal therapy compared with observation after radical prostatectomy and pelvic lymphadenectomy in men with node-positive prostate cancer. N Engl J Med. 1999;341(24):1781-1788.

7. Bolla M, Gonzalez D, Warde P, et al. Improved survival in patients with locally advanced prostate cancer treated with radiotherapy and goserelin. N Engl J Med. 1997;337(5):295-300.

8. Bolla M, Van Tienhoven G, Warde P, et al. External irradiation with or without long-term androgen suppression for prostate cancer with high metastatic risk: 10-year results of an EORTC randomised study. Lancet Oncol. 2010;11(11):1066-1073.

9. Widmark A, Klepp O, Solberg A, et al. Endocrine treatment, with or without radiotherapy, in locally advanced prostate cancer (SPCG-7/SFUO-3): an open randomised phase III trial. Lancet. 2009;373(9660):301-308.

10. Schroder FH, Kurth KH, Fossa SD, et al. Early versus delayed endocrine treatment of T2-T3 pN1-3 M0 prostate cancer without local treatment of the primary tumour: final results of European Organisation for the Research and Treatment of Cancer protocol 30846 after 13 years of follow-up (a randomised controlled trial). Eur Urol. 2009;55(1):14-22.

11. Lu-Yao GL, Albertsen PC, Moore DF, et al. Survival following primary androgen deprivation therapy among men with localized prostate cancer. JAMA. 2008;300(2):173-181.

12. Wong YN, Freedland SJ, Egleston B, Vapiwala N, Uzzo R, Armstrong K. The role of primary androgen deprivation therapy in localized prostate cancer. Eur Urol. 2009;56(4):609-616.
13. Wilt TJ, Brawer MK, Barry MJ, et al. The Prostate Cancer Intervention Versus Observation Trial:VA/NCI/AHRQ Cooperative Studies Program \#407 (PIVOT): design and baseline results of a randomized controlled trial comparing radical prostatectomy to watchful waiting for men with clinically localized prostate cancer. Contemp Clin Trials. 2009;30(1):81-87.

14. Bill-Axelson A, Holmberg L, Filen F, et al. Radical prostatectomy versus watchful waiting in localized prostate cancer: the Scandinavian prostate cancer group-4 randomized trial. J Natl Cancer Inst. 2008;100(16):1144-1154

15. Donovan JL, Peters TJ, Noble S, et al. Who can best recruit to randomized trials? Randomized trial comparing surgeons and nurses recruiting patients to a trial of treatments for localized prostate cancer (the ProtecT study). J Clin Epidemiol. 2003;56(7):605-609.

16. Shahinian VB, Kuo YF, Freeman JL, Goodwin JS. Risk of fracture after androgen deprivation for prostate cancer. $N \mathrm{Engl} \mathrm{J} \mathrm{Med}$. 2005;352(2):154-164.

17. Wong YN, Freedland S, Egleston B, Hudes G, Schwartz JS, Armstrong K. Role of androgen deprivation therapy for node-positive prostate cancer J Clin Oncol. 2009;27(1):100-105.

18. Caliendo M, Kopeinig S. Some practical guidance for the implementation of propensity score matching. J Econ Surv. 2008;22(1):31-72.

19. Kastner C, Armitage J, Kimble A, Rawal J, Carter PG, Venn S. The Charlson comorbidity score: a superior comorbidity assessment tool for the prostate cancer multidisciplinary meeting. Prostate Cancer Prostatic Dis. 2006;9(3):270-274.

20. Higano CS. Side effects of androgen deprivation therapy: monitoring and minimizing toxicity. Urology. 2003;61(2 Suppl 1):32-38.

21. Keating NL, O’Malley AJ, Smith MR. Diabetes and cardiovascular disease during androgen deprivation therapy for prostate cancer. J Clin Oncol. 2006;24(27):4448-4456.

22. Potosky AL, Reeve BB, Clegg LX, et al. Quality of life following localized prostate cancer treated initially with androgen deprivation therapy or no therapy. J Natl Cancer Inst. 2002;94(6):430-437.

23. Kawakami J, Cowan JE, Elkin EP, Latini DM, DuChane J, Carroll PR. Androgen-deprivation therapy as primary treatment for localized prostate cancer: data from Cancer of the Prostate Strategic Urologic Research Endeavor (CaPSURE). Cancer. 2006;106(8):1708-1714.

24. Elliott SP, Jarosek SL, Wilt TJ, Virnig BA. Reduction in physician reimbursement and use of hormone therapy in prostate cancer. $J$ Natl Cancer Inst. 2010;102(24):1826-1834.

25. Mendenhall WM, Nichols RC, Henderson R, Mendenhall NP. Is radical prostatectomy the "gold standard" for localized prostate cancer? Am J Clin Oncol. 2010;33(5):511-515.

26. Sanda MG, Dunn RL, Michalski J, et al. Quality of life and satisfaction with outcome among prostate-cancer survivors. $N$ Engl J Med. 2008;358(12):1250-1261.

27. Uchio EM, Aslan M, Wells CK, Calderone J, Concato J. Impact of biochemical recurrence in prostate cancer among US veterans. Arch Intern Med. 2010;170(15):1390-1395.
Comparative Effectiveness Research

\section{Publish your work in this journal}

Comparative Effectiveness Research is an international, peer reviewed open access journal focusing on comparative effectiveness of health care including preventative health care strategies, diagnostic strategies, diagnostic technology, medical devices, drugs, medical technology, health systems and organization. The manuscript management system

\section{Dovepress}

is completely online and includes a very quick and fair peer-review system. Visit http://www.dovepress.com/testimonials.php to read real quotes from published authors. 